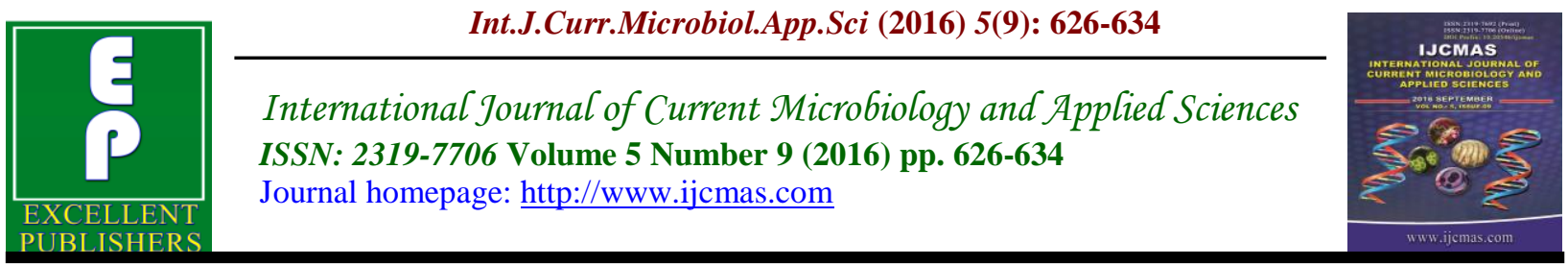

Original Research Article http://dx.doi.org/10.20546/ijcmas.2016.509.071

\title{
Textile Industries: Lead Discharge in Barnala Region, Punjab (India) - Devastating Effects on Humans
}

\author{
Yogita Sharma ${ }^{*}$, Kamalpreet Kaur ${ }^{2}$ and Vinesh Kumar ${ }^{3}$ \\ ${ }^{1}$ Associate Professor, Department of Chemistry, Guru kashi University, \\ Bathinda, Punjab, India \\ ${ }^{2}$ Research Scholar, Department of Chemistry, Guru Kashi University, Bathinda, Punjab, India \\ ${ }^{3}$ Associate Professor, Dehradun, Uttrakhand, India \\ *Corresponding author
}

\section{A B S T R A C T}

Keywords

Lead, textile industry, Atomic Absorption Spectroscopy (AAS), water, Human lives.

Article Info

Accepted:

25 August 2016

Available Online:

10 September 2016
The present study was carried out to assess the level of Lead produced by textile industries in Barnala district, Punjab (INDIA) and their harmful effects on human lives. Samples were collected from three different sites A, B and C. For each site, samples were taken from five different sources such as drain water, Surface water, Tap water, Ground water and canal. Lead can be determined by flame Atomic Absorption Spectrometer Method. Maximum value of Lead was found in site C. Lead has many harmful effects on health of children and aldults. For example Young children are particularly vulnerable to the toxic effects of lead and suffer profound and permanent adverse health effects, Particularly affecting the development of the brain and nervous System. Lead also causes long-term harm in adults, including increased risk of high blood pressure and Kidney damage. Exposure of Pregnant women to high levels of lead can cause miscarriage, Stillbirth, premature birth and low birth weight, as well as minor malformations.

\section{Introduction}

Textile processing industry is characterised not only by the large volume of water required for various unit operations but also by the variety of chemicals used for various processes. There is a long sequence of wet processing stages requiring inputs of water, chemical and energy and generating wastes at each stage. The textile industry uses high volumes of water throughout its operations, from the washing of fibres to bleaching, dyeing and washing of finished products. On average, approximately 200 litres of water are required to produce $1 \mathrm{~kg}$ of textiles.
The large volumes of wastewater generated also contain a wide variety of chemicals, used throughout processing. These can cause damage if not properly treated before being discharged into the environment. Of all the steps involved in textiles processing, wet processing creates the highest volume of wastewater.

Textile dyeing and printing industry has high importance in terms of its environmental impact, since it consumes water and produces highly polluted wastewater in large amounts. Pollutants from textile dyeing and printing industries 
vary greatly and depend on the chemicals used in various dyeing and printing processes. The receiving water thus becomes brackish. Textile dyes are toxic, highly stable and do not degrade easily and are not removed by conventional wastewater treatment methods. Due to the non degradable nature and long time persistence in the environment the toxic waste often accumulates through tropic level causing a deleterious biological effect (Kannan et al., 2005).

This study involves the assessment of level of Lead produced by textile industries in barnala region. Lead is a cumulative toxicant that affects multiple body systems and is particularly harmful to young children.

Lead exposure is estimated to account for 674000 deaths per year with the highest burden in low- and middle-income countries. Lead exposure is estimated to account for $9.8 \%$ of the global burden of idiopathic intellectual disability, $4 \%$ of the global burden of ischaemic heart disease, and $5 \%$ of the global burden of stroke. Lead in the body is distributed to the brain, liver, kidney and bones. It is stored in the teeth and bones, where it accumulates over time. Human exposure is usually assessed through the measurement of lead in blood. There is no known level of lead exposure that is considered safe.

Lead is a naturally occurring toxic metal found in the Earth's crust. Its widespread use has resulted in extensive environmental contamination.

Health experts agree that any level of lead in one's blood, no matter how small, is cause for concern. Each year in the United States, 310,0001 - to 5-year-old kids are found to have unsafe levels of lead in their blood, which can lead to a wide range of symptoms, from headaches and stomach pain to behavioral problems and anemia (not enough healthy red blood cells). Lead also can affect a child's developing brain. Lead is not only a heavy metal-it's a heavy burden on human health and the environment.

In a sense, the problem is one of our own making. The metal exists in the earth's crust in relatively small amounts, but we've been mining it from below the surface and releasing this toxic chemical into our environment for five millennia. The dangers posed by lead have been recognized since the second century B.C. But in recent years, science has shown us that even low-level lead exposure can cause neurological and cardiovascular disease, infertility, and decreased kidney function. In young children especially, traces of the metal have been linked to learning and behavioral problems, lower IQ, and other health issues that can last a lifetime.

\section{Materials and Methods}

Barnala is situated between $30^{\circ} 23^{\prime}$ North and $75^{\circ} 33^{\prime}$ 'East. It has a mean elevation of 227 metres (745 feet). It is located on the Bathinda-chandigarh highway (no-7) and the Jalander-Rewari national highway (no-71). The Sirsa-Ludhiana state highway (no-13) are passes through it. It is $65 \mathrm{~km}$ from Bathinda and $85 \mathrm{~km}$ from Ludhiana. According to 2011 census, the total population of Barnala district is 595527.It was 526931 in 2001. Water samples were collected from different water sources (Drain water, surface water, tap water, canal, ground water) from three different sites. The Sampling time was between 4:30 pm to 5:30 pm on 18 march, 2016. Plastic bottles were used to collect water samples. Testing was done in Environ Tech Laboratories (NABL Accredited laboratory) Department of 
Science and technology, India S.A.S Nagar (Mohali), Punjab.

\section{Determination of Lead by Flame Atomic Absorption Spectrometer Method-}

Preservation- samples was Preserved immediately after sampling by acidifying with conc. nitric acid to $\mathrm{pH}<2.0 .1 .5-3.0 \mathrm{ml}$ conc. $\mathrm{HNO}_{3}$ for 1 liter sample was used for short term preservation. After acidifying sample, it was preferably stored in refrigerator at approximately $4^{\circ} \mathrm{C}$.

Cleaning of Sample container-Sample containers were cleaned thoroughly with a metal-free non-ionic detergent solution, rinsed with tap water, soaked in acid, and then rinsed with metal free water. Glass material was used, for glass materials $1+1$ $\mathrm{HNO}_{3}, 1+1 \mathrm{HCl}$ was used for soaking.

\section{Digestion for flame atomic absorption and high level conc.-}

Apparatus-Hotplate, conical flask$125 \mathrm{ml}, 150 \mathrm{ml}$, acid washed and rinsed with water, volumetric flask-100ml capacity, watch glass.

Reagents-conc. Nitric acid (AR grade), $\mathrm{HCl}$ conc.(AR grade), $\mathrm{K}_{2} \mathrm{Cr}_{2} \mathrm{O} 7$, metal free double distilled water.

Nitric acid digestion-A measured volume $100 \mathrm{ml}$ of well mixed acid preserved sample was transferred to a conical flask or beaker. In a hood, $5 \mathrm{ml}$ of conc. $\mathrm{HNO}_{3}$ and boiling chips (glass beads) were added. Brought to a reflux temp. Of approximately $95^{\circ} \mathrm{C}$ to achieve a slow boil and evaporated on a hot plate to a lowest volume possible (about 10$20 \mathrm{ml}$ ) before precipitation occurred. Washed down flask or beaker walls and watch glass covered with metal free distilled water.

Then filtered. Filterate was transferred to a $100 \mathrm{ml}$ volumetric flask with two portions of reagent water. Diluted to a mark and mixed thoroughly. Portions of this solution was taken for Lead determination.

Nitric acid-hydrochloric acid digestionA measured volume of well mixed, acid preserved sample for the expected metal conc. Was transferred to a conical flask or beaker. In a hood $3 \mathrm{ml}$ of conc. $\mathrm{HNO}_{3}$ was added and covered with a ribbed watch glass. Flask or beaker was placed on a hot plate and cautiously evaporated to less than $5 \mathrm{ml}$. cooled and rinsed down wall of beaker and watch glass with a minimum of metal free water, $5 \mathrm{ml}$ of conc. $\mathrm{HNO}_{3}$ was added and covered with wath glass and again placed on hot plate. Increased temp. of hot plate so that a gentle reflux action occurred. cooled, then added $10 \mathrm{ml}(1+1) \mathrm{HCl}$ and 15 $\mathrm{ml}$ water and $15 \mathrm{ml}$ water per $100 \mathrm{ml}$ anticipated final volume. Heated for an additional 15 minutes to dissolve any precipitate or residue. Cooled and washed down beaker/ conical flask walls and watch glass with water, Filtered to remove insoluble material that could clog the nebulizer and transferred filterate to a $100 \mathrm{ml}$ volumetric flask with rinsing. Adjusted to volume and mixed thoroughly.

Interferences and elimination-Atomic absorption is a very specific technique with a few interferences. Since the interference in atomic absorption are well defined, it is easy to eliminate them.

In case of Lead there is no cationic interference but several anionic ones. At high conc. of $\mathrm{PO} 4, \mathrm{CO}_{3}$, Iodide, $\mathrm{F}$ and acetate anions can depress the Lead signals. This interference can be alleviated by the addition of 0.1 M EDTA.

\section{Preparation of Standard of Lead-}

Dissolve $1.598 \mathrm{gm}$ of lead nitrate in $1 \%$ $\mathrm{HNO}_{3}$. Dilute it to 1 liter to give $1000 \mathrm{ppm}$ lead solution. 


\section{Results and Discussion}

Different water samples for determination of lead of site A are presented in Table 1.

In case of site A the values of Lead of the water samples ranged from $0.1115 \mathrm{mg} / \mathrm{l}$ to $0.1411 \mathrm{mg} / \mathrm{l}$ with an average value of 0.1232 $\mathrm{mg} / \mathrm{l},(\mathrm{N}=5)$.The highest value of Lead was found in Drain water and lowest value of Lead was found in water sample taken from Tap water and canal. In case of site B the values of Lead of the water samples ranged from $0.103 \mathrm{mg} / \mathrm{l}$ to $0.116 \mathrm{mg} / \mathrm{l}$ with an average value of $0.109 \mathrm{mg} / \mathrm{l}(\mathrm{N}=5)$. In case of site $\mathrm{C}$ the values of Lead of the water samples ranged from $0.1982 \mathrm{mg} / \mathrm{l}$ to 0.2096 $\mathrm{mg} / \mathrm{l}$ with an average value of $0.2028 \mathrm{mg} / \mathrm{l}$, $(\mathrm{N}=5)$.

\section{Harmful effects of Lead on humans-}

Health effects from prolonged exposure to lead

A person who is exposed to lead over time may feel:

$\begin{array}{ll}\begin{array}{l}\text { Abdominal pain } \\ \text { Constipated }\end{array} & \begin{array}{l}\text { headache } \\ \text { diminished cognitive } \\ \text { Depressed }\end{array} \\ \text { Distracted } & \begin{array}{l}\text { performance } \\ \text { diminished hand dexterity } \\ \text { Forgetful }\end{array} \\ \text { drritable } & \begin{array}{l}\text { diminished reaction time } \\ \text { diminhed visual motor }\end{array} \\ \text { Nauseous/Sick, decreased libido } & \begin{array}{l}\text { performance } \\ \text { dizziness }\end{array} \\ & \text { developmental delay } \\ \text { malaise } & \text { seizures and unconsciousness (in } \\ \text { paresthesia } & \text { cases of extremely high lead } \\ \text { reduced IQ scores } & \text { levels) } \\ \text { weakness, decreased bone and } & \\ \text { muscle growth } & \text { irritability or behavioral } \\ \text { poor muscle coordination } & \text { problems } \\ \text { damage to the nervous system, } & \text { difficulty concentrating } \\ \text { kidneys, and/or hearing } & \text { headaches } \\ \text { speech and language problems } & \text { loss of appetite }\end{array}$

fatigue forgetfulness impaired concentration impotence increased nervousness irritability lethargy

weight loss sluggishness or fatigue abdominal pain vomiting or nausea constipation pallor (pale skin) from anemia metallic taste in mo

\section{Harmful effects of Lead in adults-}

\section{Kidneys}

Kidney damage occurs with exposure to high levels of lead, and evidence suggests that lower levels can damage kidneys as well (Wright et al., 1984). The toxic effect of lead causes nephropathy and may cause Fanconi syndrome, in which the proximal tubular function of the kidney is impaired (Lin et al., 1994). Long-term exposure at levels lower than those that cause lead nephropathy have also been reported as nephrotoxic in patients from developed countries that had chronic kidney disease or were at risk because of hypertension or diabetes mellitus. Lead poisoning inhibits excretion of the waste product urate and causes a predisposition for gout, in which urate builds up (Shadick $e t$ al., 2000). This condition is known as saturnine gout. 


\section{Cardiovascular system}

Evidence suggests lead exposure is associated with high blood pressure, and studies have also found connections between lead exposure and coronary heart disease, heart rate variability, and death from stroke, but this evidence is more limited. People who have been exposed to higher concentrations of lead may be at a higher risk for cardiac autonomic dysfunction on days when ozone and fine particles are higher (Pokras et al., 2008).

\section{Reproductive system}

Lead affects both the male and female reproductive systems. In men, when blood lead levels exceed $40 \mu \mathrm{g} / \mathrm{dL}$, sperm count is reduced and changes occur in volume of sperm, their motility, and their morphology. A pregnant woman's elevated blood lead level can lead to miscarriage, prematurity, low birth weight, and problems with development during childhood. Lead is able to pass through the placenta and into breast milk, and blood lead levels in mothers and infants are usually similar. A fetus may be poisoned in utero if lead from the mother's bones is subsequently mobilized by the changes in metabolism due to pregnancy; increased calcium intake in pregnancy may help mitigate this phenomenon.

\section{Nervous system}

The brains of adults who were exposed to lead as children show decreased volume, especially in the prefrontal cortex, on MRI. Areas of volume loss are shown in color over a template of a normal brain (Staudinger et al., 1998). Lead affects the peripheral nervous system (especially motor nerves) and the central nervous system (Lanphear et al., 2005). Peripheral nervous system effects are more prominent in adults and central nervous system effects are more prominent in children. Lead causes the axons of nerve cells to degenerate and lose their myelin coats (Bellinger, 2005).

Lead exposure in young children has been linked to learning disabilities, and children with blood lead concentrations greater than $10 \mu \mathrm{g} / \mathrm{dL}$ are in danger of developmental disabilities. Increased blood lead level in children has been correlated with decreases in intelligence, nonverbal reasoning, shortterm memory, attention, reading and arithmetic ability, fine motor skills, emotional regulation, and social engagement. The effect of lead on children's cognitive abilities takes place at very low levels (Nevin, 2007). There is apparently no lower threshold to the dose-response relationship (unlike other heavy metals such as mercury). Reduced academic performance has been associated with lead exposure even at blood lead levels lower than $5 \mu \mathrm{g} / \mathrm{dL}$. Blood lead levels below 10 $\mu \mathrm{g} / \mathrm{dL}$ have been reported to be associated with lower IQ and behavior problems such as aggression, in proportion with blood lead levels. Between the blood lead levels of 5 and $35 \mu \mathrm{g} / \mathrm{dL}$, an IQ decrease of 2-4 points for each $\mu \mathrm{g} / \mathrm{dL}$ increase is reported in children.

High blood lead levels in adults are also associated with decreases in cognitive performance and with psychiatric symptoms such as depression and anxiety. It was found in a large group of current and former inorganic lead workers in Korea that blood lead levels in the range of $20-50 \mu \mathrm{g} / \mathrm{dL}$ were correlated with neuro-cognitive defects.Increases in blood lead levels from about 50 to about $100 \mu \mathrm{g} / \mathrm{dL}$ in adults have been found to be associated with persistent, and possibly permanent, impairment of central nervous system function.(2) 


\section{Other Harmful effects of Lead in adults-}

Neurological Effects

Peripheral neuropathy

Fatigue / Irritability

Impaired concentration

Hearing loss

Wrist / Foot drop

Seizures

Encephalopathy

Gastrointestinal Effects

Nausea
Dyspepsia

Constipation

Colic

Lead line on gingival tissue

Reproductive Effects

Miscarriages/Stillbirths

Reduced sperm count \& motility

Abnormal sperm

Heme Synthesis

Anemia
Erythrocyte protoporphyrin

elevation

Renal Effects

Chronic nephropathy with proximal tubular damage

Hypertension

Other

Arthralgia

Myalgia

Table 1 of Site A

\begin{tabular}{|c|c|}
\hline Water samples & Conc. of Lead (mg/l) \\
\hline Drain water & 0.1411 \\
\hline Surface water & 0.1118 \\
\hline Tap water & 0.1115 \\
\hline Ground water & 0.1401 \\
\hline Canal & 0.1115 \\
\hline Mean & 0.1232 \\
\hline
\end{tabular}

Table 2 of Site B

\begin{tabular}{|c|c|}
\hline Water samples & Conc. of Lead (mg/l) \\
\hline Drain water & 0.116 \\
\hline Surface water & 0.106 \\
\hline Tap water & 0.103 \\
\hline Ground water & 0.115 \\
\hline Canal & 0.105 \\
\hline Mean & 0.109 \\
\hline
\end{tabular}

Table 3 of Site C

\begin{tabular}{|c|c|}
\hline Water samples & Conc. of Lead (mg/l) \\
\hline Drain water & 0.2096 \\
\hline Surface water & 0.1983 \\
\hline Tap water & 0.1982 \\
\hline Ground water & 0.2093 \\
\hline canal & 0.1989 \\
\hline Mean & 0.2028 \\
\hline
\end{tabular}




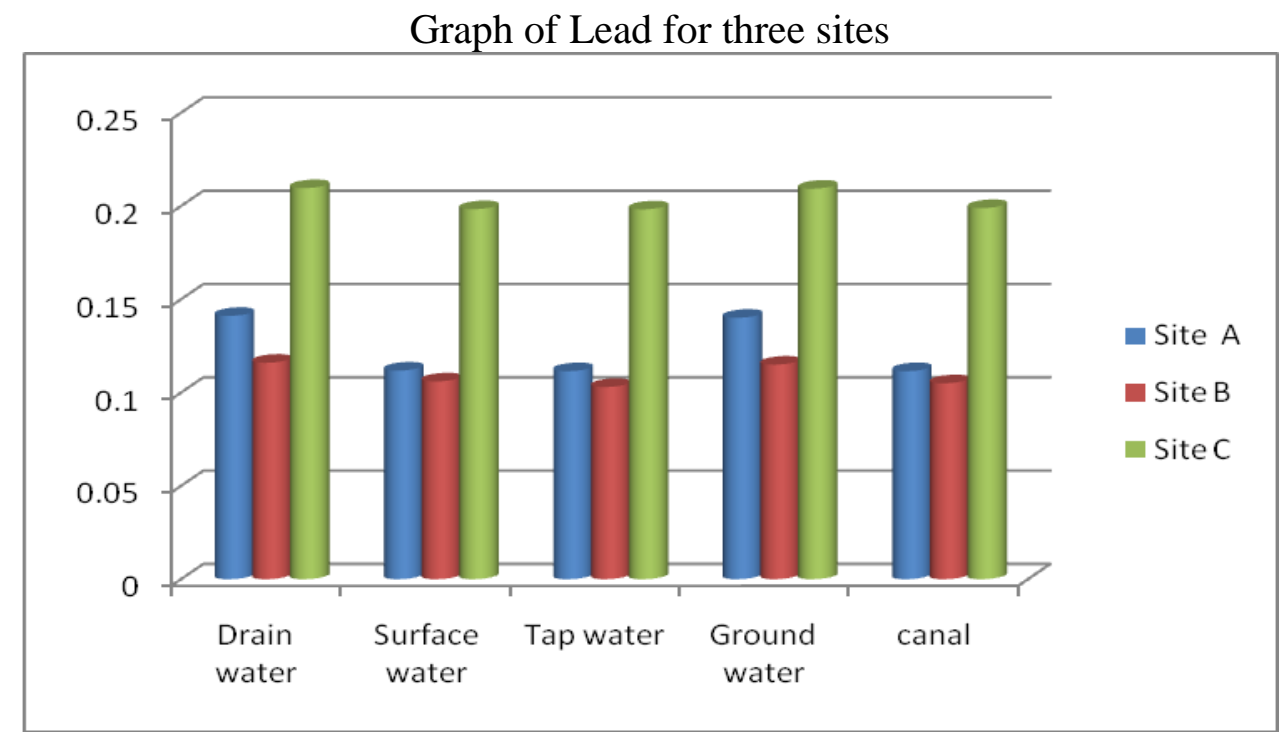

People with prolonged exposure to lead may also be at risk for high blood pressure, heart disease, kidney disease, and reduced fertility.

\section{Effects on children}

A fetus developing in the womb of a woman who has elevated blood lead level is susceptible to lead poisoning by intrauterine exposure, and is at greater risk of being born prematurely or with a low birth weight (Vedantam et al., 2007).

Children are more at risk for lead poisoning because their smaller bodies are in a continuous state of growth and development. Lead is absorbed at a faster rate compared to adults, which causes more physical harm than to older people. Furthermore, children, especially as they are learning to crawl and walk, are constantly on the floor and therefore more prone to ingesting and inhaling dust that is contaminated with lead (Park et al., 2008).

The classic signs and symptoms in children are loss of appetite, abdominal pain, vomiting, weight loss, constipation, anemia, kidney failure, irritability, lethargy, learning disabilities, and behavioral problems. Slow development of normal childhood behaviors, such as talking and use of words, and permanent intellectual disability are both commonly seen. Although less common, it is possible for fingernails to develop leukonychia striata if exposed to abnormally high lead concentrations.

\section{Complications}

Lead affects every one of the body's organ systems, especially the nervous system, but also the bones and teeth, the kidneys, and the cardiovascular, immune, and reproductive systems. Hearing loss and tooth decay have been linked to lead exposure (Kosnett et al., 2007), as have cataracts. Intrauterine and neonatal lead exposure promote tooth decay. Aside from the developmental effects unique to young children, the health effects experienced by adults are similar to those in children, although the thresholds are generally higher.

In conclusion, from the above result and discussion it is concluded that values of Lead are higher than standard values in barnala region in three different sites.Due to higher values of Lead, People may suffer 
from many harmful diseases mostly in children, Lead is absorbed at a faster rate compared to adults, which causes more physical harm than to older people. Adults may suffer from complication in kidneys, Cardiovascular system, Reproductive system and Nervous system.

\section{Acknowledgments}

I would like to thank Dr.YogitaSharma, Associate Professor, Guru Kashi University, Bathinda for giving me valuable guidance and suggestions during this study.

\section{References}

Staudinger, K.C., Roth, V.S. 1998. Balmes, John, ed. "Decreased Brain Volume in Adults with Childhood Lead Exposure". PLOS Med., 5 (5): e112. doi:10.1371/journal.pmed. 0050112. PMC 2689675. PMID 18507499.

Lanphear, B.P., Hornung, R., Khoury, J., Yolton, K., Baghurst, P., Bellinger, D.C., Canfield, R.L., Dietrich, K.N. et al. 2005. New and evolving concepts in the neurotoxicology of lead". Toxicol. Appl. Pharmacol., 225(1): 127. doi:10.1016/j.taap.2007.08.001. PMID 17904601.

Wright, L.F., Saylor, R.P., Cecere, F.A. 1984. Lead-related nephrotoxicity: a review of the epidemiologic evidence". Kidney Int., 70(12): 207484. doi:10.1038/sj.ki.5001809. PMID 17063179.

Lin, J.L., Huang, P.T. 1994. Occult lead intoxication in patients with gout and kidney disease. J. Rheumatol., 11(4): 517-20. PMID 6434739.

Shadick, N.A., Kim, R., Weiss, S., Liang, M.H., Sparrow, D., Hu, H. 2000. Body lead stores and urate excretion in men with chronic renal disease. $J$. Rheumatol., 21(4): 705-9. PMID
8035397.

Wright, L.F., Saylor, R.P., Cecere, F.A. 1984. Lead-related nephrotoxicity: a review of the epidemiologic evidence. Kidney Int., 70(12): 2074-84. doi:10.1038/sj.ki.5001809. PMID 17063179.

Lin, J.L., Huang, P.T. 1994. Occult lead intoxication in patients with gout and kidney disease". J. Rheumatol., 11(4): 517-20. PMID 6434739.

Nevin, R. 2007. How lead exposure relates to temporal changes in IQ, violent crime, and unwed pregnancy. Environ. Res., $83(1)$ : 1-22. Bibcode: 2000ER.....83....1N.doi:10.1006/enrs.1 999.4045. PMID 10845777.

Vedantam, Shankar. 2007. Understanding international crime trends: the legacy of preschool lead exposure. Environ. Res., 104(3): 315-36. Bibcode: 2007ER..104..315N.

doi:10.1016/j.envres.2007.02.008. PMID 17451672.

Pokras, M.A., Kneeland, M.R. 2008. LowLevel Environmental Lead Exposure and Children's Intellectual Function: An International Pooled Analysis". Environ. Health Perspectives, 113(7): 894-9. doi:10.1289/ehp.7688. PMC 1257652. PMID 16002379.

Kosnett, M.J., Wedeen, R.P., Rothenberg, S.J., Hipkins, K.L., Materna, B.L., Schwartz, B.S., Hu, H., Woolf, A. 2007. Cumulative Lead Dose and Cognitive Function in Adults: A Review of Studies That Measured Both Blood Lead and Bone Lead". Environ. Health Perspectives, 115(3): 483-92. doi:10.1289/ehp.9786. PMC 1849945. PMID 17431502.

Bellinger, D.C. 2005. Lead hazards for pregnant women and children: part 1: immigrants and the poor shoulder most of the burden of lead exposure in this country. Part 1 of a two-part 
article details how exposure happens, whom it affects, and the harm it can do". American J. Nursing, 108(10): 40-9; quiz 50. doi:10.1097/ 01.NAJ.0000337736.76730.66. PMID 18827541.

Park, S.K., O'Neill, M.S., Vokonas, P.S., Sparrow, D., Wright, R.O., Coull, B., Nie, H., Hu, H., et al. 2008. Lead Exposure and Cardiovascular DiseaseA Systematic Review. Environ. Health Perspectives, 115(3): 472-82. doi:10.1289/ehp.9785. PMC 1849948. PMID 17431501.

Goyer, R.A. 1990. Lead in enamel and saliva, dental caries, and the use of enamel biopsies for mesuring past exposure to lead" (PDF). J. Dent. Res., 5(10): 1165-1171. doi:10.1177/0022 0345770560100701 .

PMID 272374.Transplacental transport of lead.

Needleman, H.L., Schell, A., Bellinger, D., Leviton, A., Allred, E.N. 1990. Very low lead exposures and children's neurodevelopment. Curr. Opi. Pediatrics, 20(2): 172-7. doi:10.1097/ MOP.0b013e3282f4f97b.

PMID 18332714

Woolf, A.D., Goldman, R., Bellinger, D.C. 2007. Absorption of lead from dust and soil". Postgrad Med. J., 51(601): 801-4. doi:10.1136/pgmj.51.601.801. PMC 2496115. PMID 1208289.

Kannan, V., R. Ramesh and C. Sasikumar. 2005. Study on ground water characteristics and the effects of discharged effluents from textile units at Karur District. J. Environ. Biol., 26: 269-272.

Yogita Sharma, Kamalpreet kaur and Vinesh kumar. Textile effluents changes Physico-chemical Parameters of water in Barnala region : Threat for human lives". International conference on Innovative Research in Material Sciences, Energy Technologies and Environmental Engineering for climate change Mitigation, (New Delhi)

Yogita Sharma, Kamalpreet kaur and Vinesh kumar, "An Assessment of Physicochemical Parameters of water in Barnala Region: Risk to human lives". International conference on Recent Innovations In Sciences, Management, Education and Technology.

Yogita Sharma and Kamalpreet kaur. Determination of Nitrates and Sulphates in water of Barnala region and their harmful effects on human lives. Int. J. Adv. Res. Edu. Technol.,

\section{How to cite this article:}

Yogita Sharma, Kamalpreet Kaur and Vinesh Kumar. 2016. Textile Industries: Lead Discharge in Barnala Region, Punjab (India)-Devastating Effects on Humans. Int.J.Curr.Microbiol.App.Sci. 5(9): 624-634. doi: http://dx.doi.org/10.20546/ijcmas.2016.509.071 